\title{
Review
}

\section{Mechanisms of apoptosis induction by the HIV-1 envelope}

\author{
J-L Perfettini ${ }^{1}, M_{\text {Castedo }}{ }^{1}$, T Roumier $^{1}, \mathrm{~K}_{\text {Andreau }}{ }^{1}$, \\ R Nardacci ${ }^{2}$, M Piacentini ${ }^{2}$ and G Kroemer ${ }^{\star, 1}$ \\ 1 CNRS-UMR8125, Institut Gustave Roussy, 39 rue Camille-Desmoulins, \\ Villejuif, France; \\ 2 National Institute for Infectious Diseases IRCCS 'L Spallanzani', Via Portuense \\ 292, Rome, Italy \\ * Corresponding author: G Kroemer, CNRS-UMR 8125, Institut Gustave \\ Roussy, Pavillon de Recherche 1, 39 rue Camille-Desmoulins, F-94805 \\ Villejuif, France. Tel: 331421160 46; Fax: 331421160 47; \\ E-mail: kroemer@igr.fr
}

Received 10.10.04; accepted 10.12.04; published online 18.2.05

Edited by RA Knight

\begin{abstract}
The envelope glycoprotein complex (Env) of human immunodeficiency virus-1 (HIV-1) can induce apoptosis by a cornucopia of distinct mechanisms. A soluble Env derivative, gp120, can kill cells through signals that are transmitted by chemokine receptors such as CXCR4. Cell surface-bound Env (gp120/gp41), as present on the plasma membrane of HIV-1infected cells, can kill uninfected bystander cells expressing CD4 and CXCR4 (or similar chemokine receptors, depending on the Env variant) by at least three different mechanisms. First, a transient interaction involving the exchange of lipids between the two interacting cells ('the kiss of death') may lead to the selective death of single CD4-expressing target cells. Second, fusion of the interacting cells may lead to the formation of syncytia which then succumb to apoptosis in a complex pathway involving the activation of several kinases (cyclin-dependent kinase-1, Cdk1; checkpoint kinase-2, Chk2; mammalian target of rapamycin, mTOR; p38 mitogen-activated protein kinase, p38 MAPK; inhibitor of NF- $\kappa$ B kinase, IKK), as well as the activation of several transcription factors (NF- $\kappa \mathrm{B}$, p53), finally resulting in the activation of the mitochondrial pathway of apoptosis. Third, if the Env-expressing cell is at an early stage of imminent apoptosis, its fusion with a CD4expressing target cell can precipitate the death of both cells, through a process that may be considered as contagious apoptosis and which does not involve Cdk1, mTOR, p38 nor p53, yet does involve mitochondria. Activation of some of the above- mentioned lethal signal transducers have been detected in patients' tissues, suggesting that HIV-1 may indeed trigger apoptosis through molecules whose implication in Envinduced killing has initially been discovered in vitro.
\end{abstract}

Cell Death and Differentiation (2005) 12, 916-923.

doi:10.1038/sj.cdd.4401584

Published online 18 February 2005
Keywords: AIDS; gp41; gp120; mitochondria; p53; programmed cell death

Abbreviations: AIDS, acquired immunodeficiency syndrome; Cdk1, cyclin-dependent kinase-1; Cyt $c$, cytochrome $c$; Env, envelope glycoprotein complex; HIV-1, human immunodeficiency virus-1; mTOR, mammalian target of rapamycin; p38T180/ $\mathrm{Y} 182 \mathrm{P}, \mathrm{p} 38$ with phosphorylated threonine 180 and tyrosine 182; p53S15P, p53 with phosphorylated serine 15; p53S46P, p53 with phosphorylated serine 46; siRNA, small interfering RNA; Z-VAD.fmk, $\quad \mathrm{N}$-benzyloxycarbonyl-Val-Ala-Asp-fluoromethylketone

\section{Introduction}

Viral infection can actively elicit apoptosis, in particular at late stages of the viral life cycle when viral spreading and/or subversion of the host's immune system can help the virus to colonize its host. In accord with this general rule, the acquired immunodeficiency syndrome (AIDS) caused by human immunodeficiency virus ${ }^{-1}$ (HIV-1) involves the apoptotic destruction of infected cells ('direct killing') and of noninfected cells many of which are immunologically relevant ('bystander killing'). ${ }^{1-3}$ Without doubt, HIV-1 can induce apoptosis through a cornucopia of different mechanisms, including effects that are non-cell-autonomous and can only be studied in vivo, using material from human subjects or HIV/SIVinfected primates. ${ }^{2}$ Thus, HIV-1 has been postulated to subvert the trophic interactions among different immune cells, be they contact-dependent or be they dictated by cytokines. In addition, HIV-1 and HIV-1 products can also kill cells in vitro, in a variety of model systems that can easily be explored.

HIV-1 encodes for several apoptogenic proteins including envelop glycoprotein complex (Env), Vpr, Tat, Nef, and $\mathrm{Nfu},{ }^{1,2,4}$ as well as for at least one antiapoptotic protein, a putative glutathion peroxidase. ${ }^{5,6}$ Clinical case reports ${ }^{7}$ and epidemiological data ${ }^{8}$ that await confirmation suggest that loss-of-function mutations affecting the apoptogenic action of $\mathrm{Vpr}^{9,10}$ are more frequent in viral isolates from long-term nonprogressors (untreated patients with diagnosed HIV-1 infection for $>10$ years, with CD4 T cell count of $>500$ Cells/ $\mathrm{mm}^{3}$ ) than in patients developing AIDS. Conversely, mutations that truncate the putative glutathion peroxidase gene tend to be more frequent in AIDS patients than in long-term nonprogressors (Cohen et al., 2004), again underscoring the notion that a higher apoptogenic (or a lower antiapoptotic) potential of HIV-1 accelerates AIDS pathogenesis.

In viral infection assays involving wild-type HIV-1, the apoptogenic effect of a clinically important HIV-1-encoded protein such as $\mathrm{Vpr}^{8}$ is not observable due to the intrinsically high apoptosis-inducing effect of the HIV-1-encoded envelope glycoprotein complex (Env). Thus, the apoptogenic effect of 
Vpr is only revealed when using pseudotyped viruses, that is genetically modified HIV-1 strains in which the endogenous Env gene has been replaced by nonapoptogenic Env proteins from other viruses. ${ }^{8,11}$ This underscores the idea that Env is, at least in vitro, the principal apoptosis-inducing protein encoded by the HIV-1 genome. ${ }^{12-15}$

The Env glycoprotein (gp) precursor protein (gp160) undergoes proteolytic maturation to generate gp41 (membrane inserted) and gp120 (membrane inserted or shed from the cell surface). Soluble gp120 can stimulate proapoptotic signal via an action on chemokine receptors (CXCR4 for lymphotropic Env variants, CCR5 for monocytotropic Env variants) ${ }^{12,16,17}$ (Figure 1). Although soluble gp120 has been detected in body fluids, it has been doubted whether it would reach concentrations high enough to induce cell death in vivo. ${ }^{18}$ The membrane-anchored gp120/gp41 complex expressed on the surface of HIV-1-infected cells can induce apoptosis through an interaction with uninfected cells expressing the receptor (CD4) and the chemokine coreceptor CXCR4 or CCR5. This type of bystander killing is obtained by at least three distinct mechanisms (Figure 1). First, the two interacting cells (one which expresses Env and the other that expresses CD4 plus the coreceptor) may not fuse entirely and simply exchange plasma membrane lipids, after a sort of hemifusion process, followed by rapid death. ${ }^{19}$ Second, the interaction between the two cells can induce cellular fusion (cytogamy) ${ }^{14,15,20}$ followed by nuclear fusion (karyogamy) within the syncytium. ${ }^{21}$ Syncytia are condemned to die from apoptosis after a latency phase, presumably when conflicts in cell cycle between the daughter nuclei are detected or when the polyploidy checkpoint is activated. ${ }^{22}$ Third, it is possible that virus-infected cells, on the point of undergoing apoptosis, fuse with CD4-expressing cells, in which case apoptosis is rapidly transmitted from one cell to the other and thus occurs in a 'contagious' fashion. ${ }^{23}$

In this paper, we will review the lethal signal transduction pathways elicited by Env in vitro and discuss their possible contribution to HIV-1 pathogenesis in vivo.

\section{Cell Killing by Soluble gp120}

Soluble gp120 can induce apoptosis in lymphocytes, ${ }^{12}$ but also in neurones, ${ }^{24-27}$ cardiomyocytes, ${ }^{17,28}$ kidney epithelial cells $^{29,30}$ and hepatocytes. ${ }^{31}$ These potent cytotoxic effects have been implicated in the HIV-1-induced lymphodepletion, HIV-associated dementia (also called HIV encephalitis or neuro-AIDS), AIDS-cardiomyopathy, as well as AIDS associated nephropathy and hepatopathy.

In lymphocytes, the effect of gp120 mainly involve interactions with CD4 and CXCR4 (Figure 2). Antibody-mediated crosslinking of CD4 (or CXCR4) in the absence of CD3 stimulation can sensitize $T$ lymphocytes to apoptosis induction, ${ }^{32}$ and similar findings have been reported for the gp120mediated activation of T cells. ${ }^{33}$ Stimuli converging on CD4 may activate the CD95/CD95L-dependent death receptor pathway or, alternatively, activate the Bax-dependent mitochondrial pathway to apoptosis. ${ }^{34,35}$ In Jurkat T cells, CD4 engagement by the Leu3a mAb results in a rapid and strong increase of Lck kinase activity, its association with the T-cell

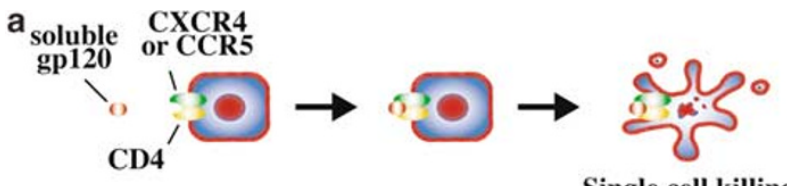

Single cell killing

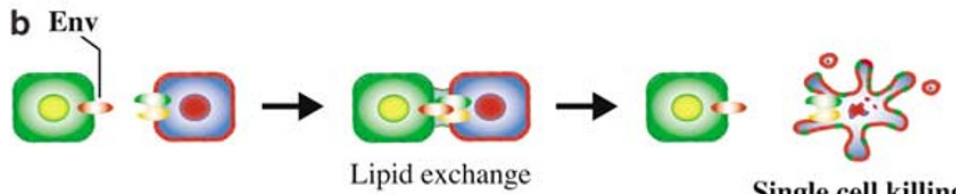

Lipid exchange Single cell killing
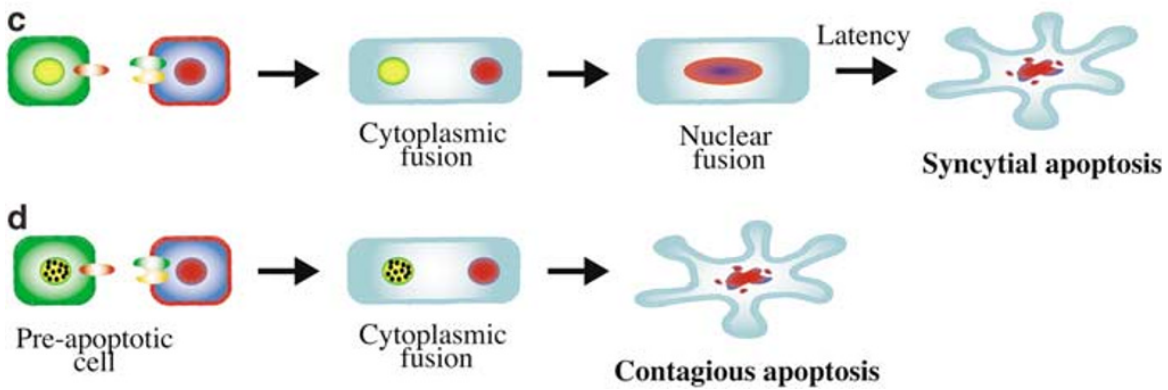

Figure 1 Four distinct mechanisms of Env-mediated killing. Soluble gp120 interacting with CD4 and chemokine receptors (CXCR4 or CCR5) can cause a single cell killing (a). Membrane-bound Env (gp120/gp41) can induce apoptosis by interactions with its receptors through at least three distinct mechanisms. First, the interaction between Env- and CD4/CXR4 (or CCR5)- overexpressing cells leads can trigger single cell killing through transient interactions with hemifusion-mediated exchange of lipids on the membranes of the interacting cells (b). Second Env-expressing cells can fuse with Env-negative cells expressing suitable combinations of receptors and coreceptors resulting in syncytium formation and death after a period of latency (c). Finally, preapoptotic Env-positive cells can kill CD4-positive cells upon fusion, in a rapid 'contagious' process (d) 


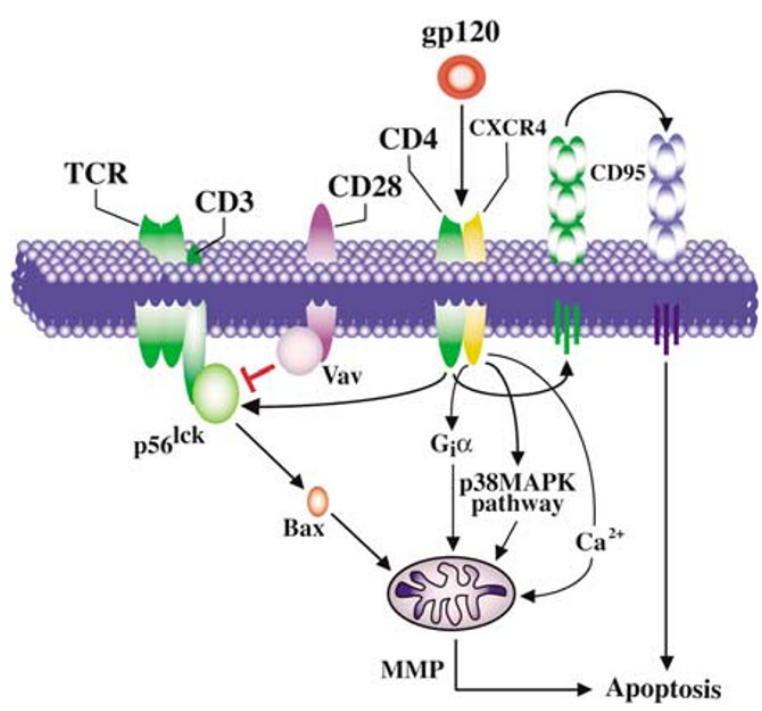

Figure 2 Mechanisms of gp120-induced killing. Soluble gp120 triggers cell death through interactions with CD4 and/or CXCR4. Binding of gp120 to CD4 may stimulate the CD95/CD95L-dependent cell death pathway or trigger a Baxdependent mitochondrial apoptosis, which requires p56lck activity. In addition, interactions between gp120 and CXCR4 can cause mitochondrial membrane permeabilization (MMP) through pertussis toxin- sensitive G proteins (Gia), p38 MAPK pathway and/or $\mathrm{Ca}^{2+}$-dependent mechanisms

receptor, upregulation of Bax, subsequent alterations of the mitochondrial transmembrane potential $\left(\Delta \Psi_{\mathrm{m}}\right)$, and apoptosis. $^{36}$ This effect can be counteracted by Vav, a signaling molecule that cooperates with CD28 to boost TCR signals. ${ }^{36}$ This may explain why CD28 can inhibit gp120-induced cell death. ${ }^{37}$ A monoclonal antibody against CXCR4 also triggers rapid T lymphocyte death preceded by $\Delta \Psi_{\mathrm{m}}$ dissipation. In this particular model, cell death occurs in a caspase-independent fashion. ${ }^{32}$ Cell lines transfected with a truncated form of CD4 that binds gp120 but lacks the ability to transduce signals (due to absence of the cytoplasmic domain of CD4), still manifest $\Delta \Psi \mathrm{m}$ dissipation in response to gp120 acting on CXCR4. ${ }^{16}$ The signal triggered by gp120 involves chemokine receptorsin neurons mainly CXCR4, ${ }^{16,17}$ and downstream of such receptors, pertussis toxin-sensitive $G$ proteins, ${ }^{17}$ the p38 mitogen-activated protein kinase pathway, ${ }^{38}$ and/or a rapid cytosolic $\mathrm{Ca}^{2+}$ increase ${ }^{39}$ (Figure 2).

Gp120 induces apoptosis of cultured neurons and sensitizes them to oxidative stress and excitotoxins. Gp120 also causes neuronal dysfunction and death in rodents in vivo. ${ }^{40}$ Specific inhibitors of both the Fas/tumor necrosis factor- $\alpha$ / death receptor pathway and the mitochondrial caspase pathway can reduce the gp120-induced neuronal apoptosis. ${ }^{40}$ When added to mixed cultures of murine neurons and glial cells, gp120 only causes apoptosis when such cells are derived from p53-expressing mice. Reconstitution experiments in which $\mathrm{p} 53^{+/+}$and $\mathrm{p} 53^{-1-}$ neurons and glial cells were mixed demonstrated that both cell types (neuronal + glial) were required for the lethal response to gp120 and that both of them had to express p53 so that neurons would die upon gp120 addition. ${ }^{25}$ Thus, p53 may participate in the proapoptotic tuning of cellular networks. An accumulation of p53 has been observed in the brain of patients with HIV-

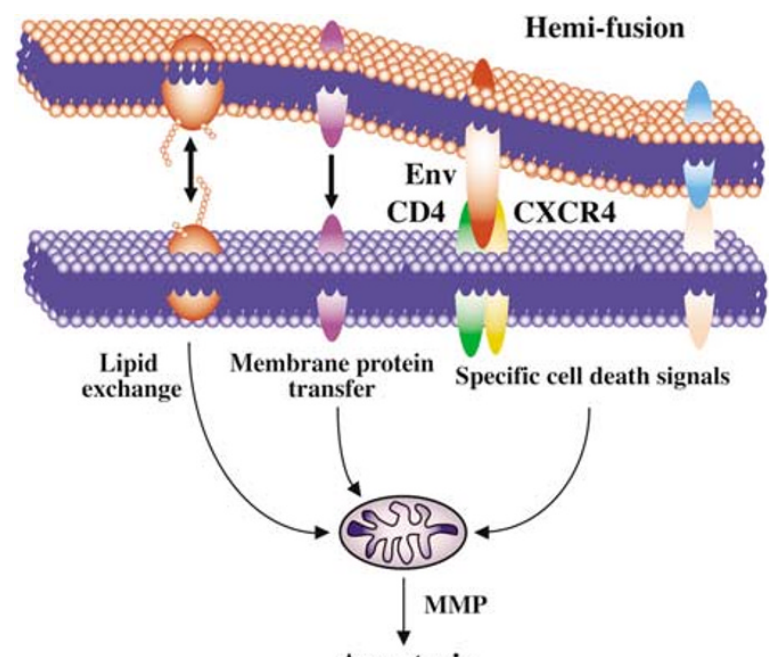

Apoptosis

Figure 3 Single cell killing triggered by cell membrane-bound Env. This process implies transient membrane contacts and hemifusion events with exchange of lipids between the interacting plasma membranes. The putative implication of membrane protein transfer and/or specific receptor-mediated death signals is also depicted

associated dementia. ${ }^{41}$ Similarly, p53 accumulates in the brain tissue from monkeys with simian immunodeficiency virus (SIV) encephalitis. ${ }^{42}$ These observations suggest that, at least in neurons, p53 may be a critical proapopotic protein elicited by HIV-1 products (and in particular gp120) in vivo.

\section{Single Cell Killing by Membrane-anchored Env: The Kiss of Death}

Bystander cells expressing CD4 and CXCR4 or CCR5 die after coculture with cells engineered to express surfacebound Env (gp120/gp41). Cell killing may be secondary to fusion of the interacting cells, but it may also affect single cells $^{16,19,43-46}$ (Figure 3). Apparently, the 'decision' whether cell fusion occurs or not is governed at the level of the CD4/ coreceptor-expressing cell, through yet-to-be-elucidated mechanisms, since different cell lines expressing such coreceptors (e.g. Jurkat cells and U937 cells) behave in a differential fashion when exposed to the same Env-expressing cell type (e.g. Env-tranfected HeLa cells) (Ferri et al., 2000a). ${ }^{45}$ Moreover, the caspase inhibitor Z-VAD.fmk, which can reduce single cell killing, reportedly increases the amount of syncytia formed in such cocultures. ${ }^{43}$ Agents that inhibit the interaction between gp120 and CD4 or CXCR4 suppress both syncytium formation and single cell killing by surface-exposed Env. ${ }^{19,43,45}$ In addition, fusion inhibitors blocking the function of gp41 (such as C34 and T-20) also block the death of single target cells. ${ }^{19,43}$

Importantly, Env-induced single cell death is associated with the gp41-mediated transfer of lipids from the membrane of Env-expressing cells to the target cell, a phenomenon which occurs without detectable cytoplasmic mixing, and thus involves a hemifusion-like event. ${ }^{19}$ However, basic information is lacking on this 'kiss of death' (Figure 3). It is not clear if surface proteins are transferred during the cell-cell contact, 
and whether a simple membrane perturbation or more specific signals lead to cell death. The exact cellular signals involved in target cell killing remain largely unexplored apart from the fact that they do not involve $\mathrm{CD}^{16}{ }^{16}$ and that they act in a rapid, pertussis toxin-resistant fashion, ${ }^{43}$ leading to $\Delta \Psi_{\mathrm{m}}$ loss and subsequent plasma membrane permeabilization. ${ }^{19,43,45}$ Overexpression of $\mathrm{Bcl}-2$ can inhibit single cell killing ${ }^{45}$ and, as mentioned above, inhibition of caspases diverts single cell killing to syncytium formation, ${ }^{43}$ suggesting that the process does follow canonical apoptotic signaling pathways (Figure 3).

\section{Syncytial Apoptosis Induced by Env}

Syncytium formation resulting from the Env/CD4 interaction leads to apoptosis, and this mode of cell death induction may participate in the AIDS-associated depletion of CD4 $+\mathrm{T}$ lymphocytes. ${ }^{15,47-50}$ A positive correlation between CD4 + T cell decline and infection by syncytium-inducing HIV-1 or SIV1 variants has been established in vitro ${ }^{15,20,48,51}$ and, more importantly, in vivo, in humans with AIDS, ${ }^{47,49}$ humanized SCID mice, ${ }^{52}$ and monkeys. ${ }^{53}$

We have studied several in vitro models of syncytial apoptosis, in particular a coculture system involving HeLa cells transfected with the HIV-1 ${ }^{\text {LAI }}$ Env gene and HeLa cells transfected with $C D 4{ }^{54}$ In such an in vitro model, apoptosis occurs only in syncytia, as a result of a stepwise process (Figure 4), affecting 50\% of the syncytia around 36-48 h after their formation. After an initial stage during which the cells contain well separated nuclei with intact envelopes, nuclear fusion (karyogamy) occurs. ${ }^{21}$ This nuclear fusion is the expression of an abortive entry into the mitotic prophase stimulated by the transient activation of the cyclin Bdependent kinase-1 (Cdk1), ${ }^{55}$ accompanied by the permeabilization of the nuclear envelope, presumably due to the Cdk1-mediated phosphorylation of lamin (which favors lamin depolymerization and hence disassembly of the nuclear envelope). It is only after karyogamy has occurred that syncytia die from apoptosis. ${ }^{21,56-60}$

Molecular ordering of the process has been achieved using a systemic approach involving microarrays, macroarray, transcription factor profiling, and proteomics. This systemic approach has been complemented by hypothesis-driven research involving a battery of chemical inhibitors of kinases, microinjection of specific inhibitors (of Bax, VDAC, AIF, cytochrome $c$ (Cyt $c)$ ), transfection with dominant-negative constructs (of Cdk1, p38 MAPK, MKK3/6, and p53), as well as positive manipulations (microinjection of the cyclin B-dependent kinase-1, transfection with mammalian target of rapamycin (mTOR), microinjection of recombinant Bax or purified Cyt $c$ ). After a transient activation of the mitotic progression factor (MPF, composed of cyclin B and cyclin-dependent kinase 1, Cdk1) with activation and phosphorylation of the checkpoint kinase-2 (Chk2) ${ }^{59}$ as well as activation of $\mathrm{NF}-\kappa \mathrm{B},{ }^{61}$ cells undergo an abortive entry into the prophase of mitosis, where they arrest and manifest nuclear fusion (karyogamy) within the heterokaryon. ${ }^{21}$ It is at that point (but not during the interphase) that syncytia manifest p53 phosphorylation both on serine $15^{55,62}$ and serine $46 .{ }^{61}$ Moreover, a series of p53 target genes including two proapoptotic $\mathrm{Bcl}-2$ family numbers,

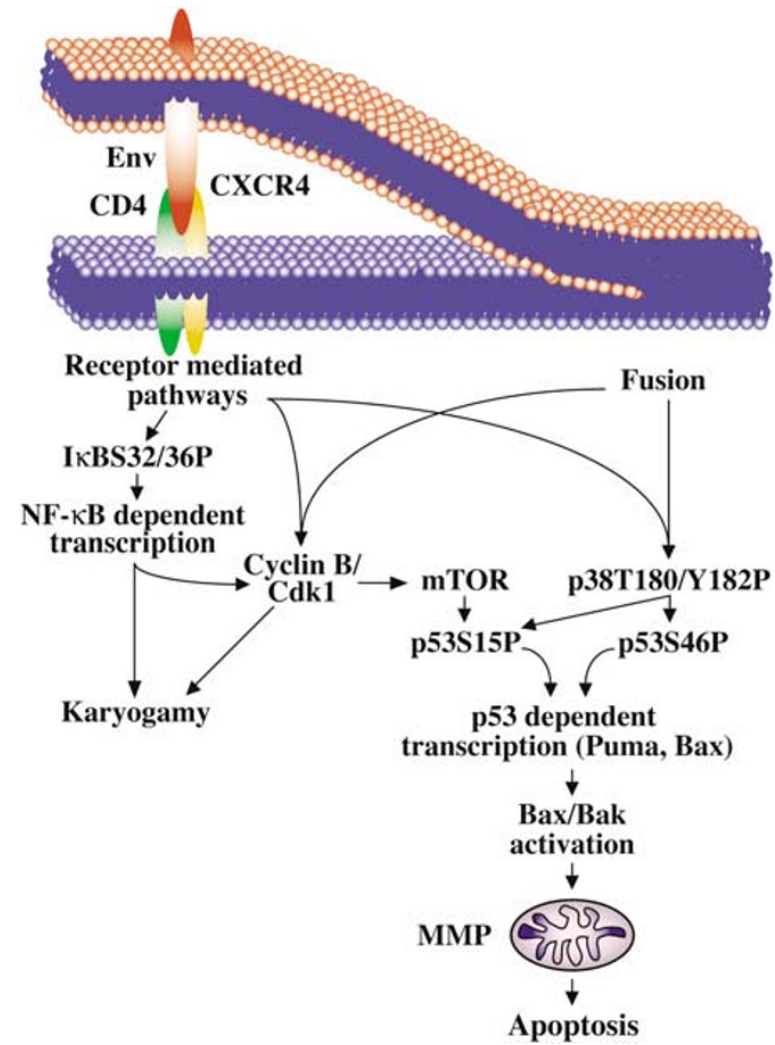

Figure 4 Mechanisms of syncytial apoptosis. Syncytia arising from the fusion of cells expressing Env with cells expressing CD4 and CXCR4 die after a latency through a mitochondrion-dependent apoptosis pathway. Specific signals mediated by plasma membrane receptor and/or a perturbation of cellular metabolism induced by the fusion event can trigger a series of proapoptotic kinases. Phosphorylation of the inhibitor of NF- $\kappa \mathrm{B}(1 \kappa \mathrm{B})$ on serine 32 and on serine 36 induces its degradation and initiates NF- $\kappa \mathrm{B}$-dependent transcription. Cyclin B-dependent kinase-1 (Cdk1) is induced and causes an abortive entry into the mitotic prophase, resulting in the fusion of several nuclei within the same cytoplasm (karyogamy). mTOR and p38MAPK, two kinases activated by cell fusion, phosphorylate p53 on serines 15 and 46 , thereby facilitating p53dependent transcription. Puma and Bax, two p53 target genes, are induced and trigger mitochondrial membrane permeabilization (MMP) and consequent caspase activation

namely Bax and Puma, are transcribed, ${ }^{55,61,62}$ thus activating the mitochondrial pathway of apoptosis with Cyt $c$-dependent caspase activation. ${ }^{21,45,63,64}$ Thus, p53 emerges as a critical mediator of syncytial apoptosis (Figure 4).

One of the p53-phosphorylating enzymes has been identified as mTOR, which is enriched in karyogamic nuclei and coimmunoprecipitates with $\mathrm{p53} .^{55,62}$ Blockade of the aberrant advancement in cell cycle, by inhibition of Cdk1, Chk2, or NF- $\kappa$ B strongly reduces the phosphorylation of $p 53$ on both $\mathrm{S} 15$ and $\mathrm{S} 46$. $^{58,59,61,62,65}$ However, inhibition of mTOR with rapamycin only partially reduced the phosphorylation of $\mathrm{p} 53$ on $\mathrm{S} 15$ (p53S15P), by about 50-60\%. ${ }^{55,61,62}$

Another p53 kinase that has been identified more recently, cytoplasmic p38 mitogen-activated protein kinase (MAPK), was found to undergo an activating phosphorylation (on T180/ $\mathrm{Y} 182 \mathrm{P}$ ) before karyogamy and to translocate into karyogamic nuclei, where p38T180/Y182P colocalized and coimmuno- 
precipitated with p53 alone. ${ }^{66}$ Activated recombinant p38 protein phosphorylated recombinant p53 on serines 15 and 46 in vitro. Inhibition of p38 MAPK by pharmacological inhibitors, dominant-negative p38, or small interfering RNA (siRNA), suppressed p53S46P (but not p53S15P), the expression of p53-inducible genes, the conformational activation of proapoptotic Bax and Bak, the release of Cyt $c$ from mitochondria, and consequent syncytial apoptosis. Importantly, we found that the combined inhibition of mTOR and p38 led to a much more pronounced reduction of p53S15P than the inhibition of mTOR alone. ${ }^{66}$ Thus, the principal p53 kinase acting on S46 is p38 MAPK, while there are at least two kinases acting on S15, namely mTOR and p38 MAPK (Figure 4).

Little is known on the upstream signals leading to the activation of mTOR or p38 MAPK. In both cases, karyogamy occurs independent from these kinases and is required for their translocation to the nucleus. Syncytium formation of HeLa CD4 cells, induced for instance by polyethyleneglycol, is sufficient to activate p38 MAPK, to phosphorylate p53 on serine 46 and to cause apoptosis, suggesting that CD4 and chemokine receptor-mediated signaling is not required for initiation of this particular proapoptotic cascade. Dominantnegative MKK3 or MKK6 inhibited syncytial activation of p38, p53S46P, and apoptosis in the HeLa CD4/HeLA Env coculture system. ${ }^{66}$ However, the exact cascade of molecular events linking syncytium formation to the activation mTOR and p38 MAPK remains to be elucidated.

Can the results obtained with cell lines engineered to overexpress the gp120/gp41 complex (that is in HIV-1-free systems) be extrapolated to the pathophysiology of HIV-1 infection? Infection of primary human lymphoblasts in vitro, with lymphotropic HIV-1 isolates, causes cell death mainly by syncytium formation, associated with a series of alterations that resemble those induced by Env in vitro, namely $\Delta \Psi_{m}$ loss, ${ }^{46,67}$ mitochondrial release of Cyt $c$ and AIF, ${ }^{67,68}$ increased ROS production, ${ }^{69}$ phosphorylation of p53 on serine $15,{ }^{55,67}$ phosphorylation of p53 on serine $46,{ }^{61}$ activation of $\mathrm{p} 38 \mathrm{MAPK},{ }^{66}$ and the p53-dependent induction of $\mathrm{Bax}^{67}$ and Puma. ${ }^{61}$ The amount of Bax is found to be increased in the mitochondrion-enriched heavy membrane fraction of HIV-infected CD4 + $\mathrm{T}$ cells as compared to uninfected controls. ${ }^{45,67}$ In vitro, pharmacological inhibition of Cdk1 (with roscovitine), ${ }^{55,62}$ mTOR (with rapamycin), ${ }^{55,62}$ p38 MAPK (with SB203580 or other inhibitors), ${ }^{66,70}$ or p53 (with cyclic pifithrin- $\alpha)^{61,62}$ suppresses the apoptosis induced by HIV-1 infection, while caspase inhibition (with Z-VAD.fmk) has no or little cytoprotective effects. ${ }^{45,68}$ Altogether, these data suggest that the cascade of events delineated above (cell fusion $\rightarrow$ activation of Cdk1/cyclin B $\rightarrow$ p53 phosphorylation on serine 15 and serine 46 by mTOR and p38 MAPK $\rightarrow$ transcriptional activation of p53 target genes such as Bax and Puma $\rightarrow$ Bax translocation to mitochondria with consequent $\mathrm{MMP} \rightarrow$ caspase independent cell death) is induced by HIV-1 infection in vitro.

A few reports suggest that the pathway delineated above is also activated in HIV-1-infected individuals, in vivo, at least in some cell types. Thus, cyclin B has been found to be overexpressed in circulating $T$ lymphocytes from HIV-1 carriers, and this upregulation disappears upon successful antiretroviral therapy. ${ }^{71,72}$ Similarly, mTOR and the phosphoneoepitope indicating phosphorylation of p53 on serine 15 were found to be overexpressed among a fraction of peripheral blood mononuclear cells, correlating with viral load, ${ }^{55,62}$ as well as with the frequency of cells expressing tissue transglutaminase-2, a marker of preapoptosis. ${ }^{73}$ Highly active antiretroviral therapy (HAART) corrected the abnormally high mTOR and p53S15P levels of the patients. ${ }^{62}$ Syncytia containing p38 with phosphorylated thereonine 180 and tyrosine 182 (p38T180/Y182P) were detected in lymph node biopsies from HIV-1 carriers, in the brain of patients with HIV-1-associated dementia, and in cocultures of HeLa expressing the HIV-1 envelope (Env) with HeLa cells expressing CD4. ${ }^{61}$ Activated, phosphorylated p53 with phosphorylated serine 46 (p53S46P) was also detected in HIV-1induced syncytia, in vivo, in patients' lymph nodes and brains from patients with HIV-1-associated dementia, yet lacked in uninfected control subjected or in brains of HIV-1-infected patients without neurodegeneration. ${ }^{66}$ Thus, it appears possible that the syncytial pathway leading to apoptosis (or a closely related pathway) is activated in vivo, in HIV-1 carriers.

\section{Contagious Apoptosis Facilitated by the HIV-1 Envelope}

HIV-1 can kill the cells that it infects (and which express Env on the surface) in a cell-autonomous fashion. We recently discovered that, when the apoptotic pathway is initiated in Env + cells ('donor cells'), coculture with a healthy CD4+ fusion partner ('acceptor cells') results in rapid apoptosis of the syncytium and thus is 'contagious'23 (Figure 5). As an initiating signal, we could use a short pulse of staurosporine treatment $(3 \mu \mathrm{M}, 3 \mathrm{~h})$ or, alternatively, actinomycin D or Vpr, meaning that different modes of apoptosis induction in 'donor' cells can trigger contagious apoptosis. The cell-to-cell transmission of the lethal signal was only observed when the nuclei from donor cells exhibited preapoptotic chromatin condensation (PACC), which precedes caspase activation, as well $\Delta \Psi_{\mathrm{m}}$ dissipation. ${ }^{74}$ However, no fusion between HeLa Env and HeLa CD4 cells and no contagious apoptosis was observed when the donor cells were already apoptotic. ${ }^{23}$ PACC marks a preapoptotic event, upstream of the mitochondrial checkpoint. Cells with PACC exhibited partial chromatin condensation with irregular nuclear contours, no Tunel staining, no DNA fragmentation detectable by conventional or pulse field gel electrophoresis, yet manifested comet assay-detectable DNA strand breaks, as well as the phosphorylation of histone $\mathrm{H} 2 \mathrm{AX}$ (on serine 139) and that of Chk2 (on threonine 68), which accumulated in discrete nuclear speckles indicative of DNA damage. ${ }^{23,74}$

Transmission of the lethal signal from PACC + cells to healthy cells resulted in mitochondrial alterations $(\triangle \Psi \mathrm{m}$ loss and Cyt $c$ release), and caspase-dependent nuclear pyknosis with chromatinolysis affecting both the donor and the acceptor nuclei. ${ }^{23}$ Thus nuclear apoptosis affected all nuclei, irrespective of their origin, within the same syncytium simultaneously. In the presence of caspase inhibitors, all nuclei of the syncytium formed by fusion of the preapoptotic Env-expressing and the healthy expressing cell manifested PACC, 


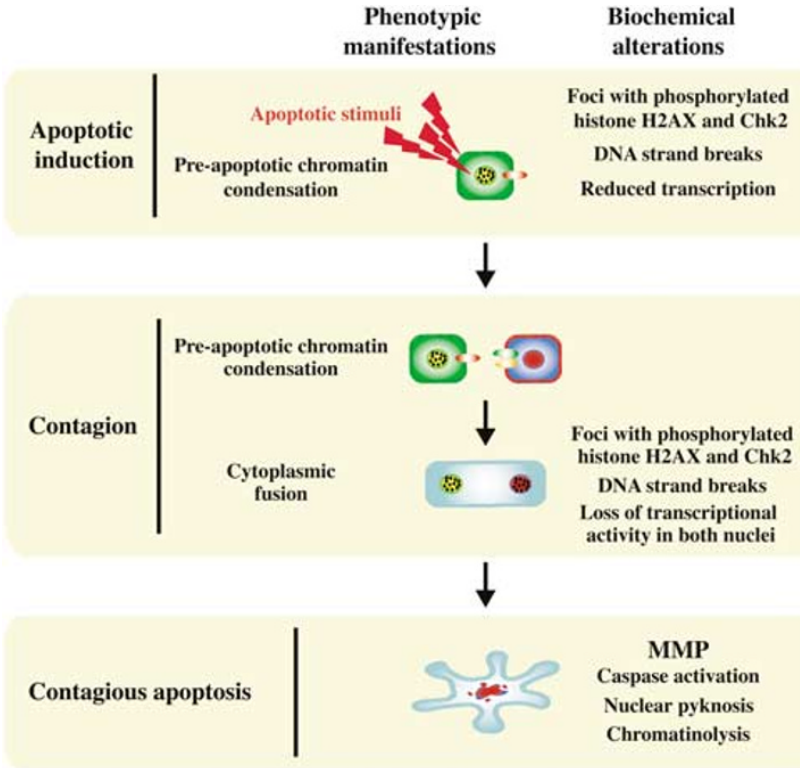

Figure 5 Mechanisms of contagious apoptosis. When apoptosis is initiated in Env + cells, preapoptotic Env + cells can fuse with healthy CD4 + cells, thus forming syncytia that die rapidly through caspase-dependent apoptosis. This 'contagious' apoptosis is exclusively observed, when treated Env + cells show a preapoptotic chromatin condensation (PACC), a phenomenon that precedes caspase activation and mitochondrial membrane permeabilization (MMP) PACC + cells manifest other biochemical alterations such as DNA strand breaks and DNA foci with phosphorylated histone H2AX on serine 135 (HZAXS139P) and Chk2 on threonine 68 (Chk2T68P). The transmission of lethal signals requires cytoplasmic (but not nuclear) fusion and leads first to PACC of the nuclei originating from the CD4 + cells and then to full-blown apoptosis with MMP, caspase activation, nuclear pyknosis, and chromatolysis

exhibited DNA lesions, and lost transcriptional activity. Transmission of the lethal signal did not require donor cells to contain a nucleus or mitochondrial DNA (and thus was independent from DNA lesions), yet was inhibited at all levels when two mitochondrion-stabilizing proteins, Bcl-2 or VMIA, were overexpressed (Figure 5). Importantly, contagious apoptosis was mechanistically different from spontaneous syncytial apoptosis because it occurred more rapidly (killing around $50 \%$ of the cells within $4-6 \mathrm{~h}$ ) and because it was not inhibited by pharmacological inhibitors of Cdk1 (e.g. roscovitine), mTOR (e.g. rapamycin), or p53 (e.g. cyclic pifithrin $\alpha)^{23}$ Thus, contagious apoptosis relies on mitochondrial permeabilization, upstream of caspase activation, linked to a yet-tobe characterized cytoplasmic event, which is different from the known actors involved in slow, spontaneous syncytial death.

We specifically investigated whether fusion was required for contagious apoptosis or whether hemifusion-like events would be sufficient for the transmission of the lethal signal, based on the knowledge that two T-lymphoid cell lines (Jurkat and CEM) fuse with HeLa Env cells, while the myelomonocytic U937 cells do not fuse with HeLa Env and rather undergo transient interactions that involve transfer of plasma membrane lipids through a hemifusion-like process, the 'kiss of death'. ${ }^{19}$ STS-pulsed HeLa Env cells with PACC did induce killing of Jurkat or CEM cells, yet had no major apoptosisinducing effect on U937 cells, in accord with the notion that fusion (rather than hemifusion) is required for cell death induction. Contagious apoptosis could be induced in primary human $\mathrm{C} 4+\mathrm{T}$ lymphocytes, as well as in vivo, in the peritoneal cavity of mice, in which human $\mathrm{T}$ cells were exposed to dying Env-expressing cells. ${ }^{23}$

Based on these data, we speculate that contagious apoptosis could potentially affect CD4 + T cells in HIV-1 infection. In conditions in which viral replication overwhelms the cellular defense response and triggers (pre-)apoptosis of the 'donor' Env + cells, fusion with 'recipient' CD4 + cells might contribute to the depletion of interacting CD4 $+\mathrm{T}$ lymphocytes by contagious apoptosis.

\section{Concluding Remarks}

The HIV-1 envelope can cause the demise of uninfected cells through a plethora of different mechanisms, as summarized in this review. At least in vitro, cells expressing the CD4 receptor and/or suitable coreceptors can die upon exposure to the soluble Env derivative gp120 or to cells expressing Env (gp120/gp41) on their surface, through a process that may or may not involve hemifusion (the 'kiss of death'), cytoplasmic and nuclear fusion ('syncytial apoptosis'), and/or rapid cell-tocell transmission of apoptotic signals ('contagious apoptosis'). Beyond Env and its coreceptors, the lethal signal transduction may involve a number of kinases (e.g. IKK, p38 MAPK, mTOR), some transcription factors (in particular, NF- $\kappa \mathrm{B}$ and p53), as well as typical ingredients of the mitochondrial apoptotic cascade (Puma, Bax, Bak, Cyto $c$, etc.).

In view of the scarcity and the cost of animal models of HIV1 infection, it will be particularly important to investigate the relative contribution of these processes and molecules to AIDS pathogenesis by careful examination of circulating cells or biopsies from HIV-1 carriers. Future will tell whether the modulation of apoptosis induced by HIV-1 (rather than the infection by HIV-1 itself) will provide some clinical benefit for the control of one of the major menaces to human longevity and civilized life.

\section{Acknowledgements}

This work has been supported by ANRS, Sidaction, as well as the European Union (Active p53).

\section{References}

1. Badley AD, Pilon AA, Landay A and Lynch DH (2000) Mechanisms of HIV-associated lymphocyte apoptosis. Blood 96: 2951-2964

2. Gougeon M (2003) Cell death and immunity: apoptosis as an HIV strategy to escape immune attack. Nat Rev Immunol 3: 392-404

3. Pantaleo G and Fauci A (1995) Apoptosis in HIV infection. Nat. Med. 1: $118-120$

4. Fauci AS (1996) Host factors and the pathogenesis of HIV-induced disease. Nature 384: 529-534

5. Cohen I, Boya P, Zhao L, Metivier D, Andreau K, Perfettini J-L, Weaver JG, Badley A, Taylor EW and Kroemer G (2004) Anti-apoptotic activity of the glutathione peroxidase homologue encoded by HIV-1. Apoptosis 9: 181-192

6. Zhao L, Cox AG, Ruziecka JA, Blat AA, Zhang W and Taylor EW (2000) Molecular modeling and in vitro activity of an HIV-1-encoded glutathione peroxidase. Proc. Natl. Acad. Sci. USA 97: 6356-6361 
7. Somasundaran M, Sharkey M, Brichacek B, Luzuriaga K, Emerman M, Sullivan $\mathrm{JL}$ and Stevenson M (2002) Evidence for a cytopathogenicity determinant in HIV-1 Vpr. Proc. Natl. Acad. Sci. USA 99: 9503-9508

8. Lum JJ, Cohen OJ, Nie Z, Weaver JG, Gomez TS, Yao XJ, Lynch D, Pilon AA, Hawley N, Kim JE, Chen Z, Montpetit M, Sanchez-Dardon J, Cohen EA and Badley AD (2003) Vpr R77Q is associated with long-term nonprogressive HIV infection and impaired induction of apoptosis. J. Clin. Invest. 111: $1547-1554$

9. Brenner C and Kroemer G (2003) The mitochondriotoxic domain of $\mathrm{Vpr}$ determines HIV-1 virulence. J. Clin. Invest. (in press)

10. Jacotot E, Ravagnan L, Loeffler M, Ferri KF, Vieira HL, Zamzami N, Costantini P, Druillennec S, Hoebeke J, Briand JP, Irinopoulou T, Daugas E, Susin SA, Cointe D, Xie ZH, Reed JC, Roques BP and Kroemer G (2000) The HIV-1 viral protein $R$ induces apoptosis via a direct effect on the mitochondrial permeability transition pore. J. Exp. Med. 191: 33-46

11. Yao XJ, Mouland AJ, Subbramanian RA, Forget J, Rougeau N, Bergeron D and Cohen EA (1998) Vpr stimulates viral expression and induces cell killing in human immunodeficiency virus type 1 -infected dividing Jurkat T cells. J. Virol. 72: $4686-4693$

12. Cicala C, Arthos J, Rubbert A, Selig S, Wildt K, Cohen OJ and Fauci AS (2000) HIV-1 envelope induces activation of caspase-3 and cleavage of focal adhesion kinase in primary human CD4+ T cells. Proc. Natl. Acad. Sci. USA 97: 1178-1183

13. Laurent Crawford AG, Krust B, Riviere $Y$, Desgranges $C$, Muller S, Kieny MP, Dauguet C and Hovanessian AG (1993) Membrane expression of HIV envelope glycoproteins triggers apoptosis in CD4 cells. AIDS Res Hum Retroviruses 9: 761-773

14. Lifson JD, Feinberg MB, Reyes GR, Rabin L, Bonapour B, Chakrabarti S, Moss B, Wong-Staal F, Steimer KS and Engleman EG (1986a) Induction of CD4dependent cell fusion by the HTLV-III/LAV envelope glycoprotein. Nature 323: 725-728

15. Sodroski JG, Goh WC, Rosen A, Campbell K and Haseltine WA (1986) Role of the HTLV/LAV envelope in syncytia formation and cytopathicity. Nature 322: 470-474

16. Roggero R, Robert-Hebmann V, Harrington S, Roland J, Verne L, Jaleco S, Devaux $C$ and Biard-Piechaczyk M (2001) Binding of human immunodeficiency virus type $1 \mathrm{gp} 120$ to CXCR4 induces mitochondrial transmembrane depolarization and cytochrome $c$-mediated apoptosis independently of Fas signaling. J. Virol. 75: 7637-7650

17. Twu C, Liu NQ, Popik W, Bukrinsky M, Sayre J, Roberts J, Rania S, Bramhandam V, Roos KP, MacLellan WR and Fiala M (2002) Cardiomyocytes undergo apoptosis in human immunodeficiency virus cardiomyopathy through mitochondrion- and death receptor-controlled pathways. Proc. Natl. Acad. Sci. USA 99: 14386-14391

18. Klasse PJ and Moore JP (2004) Is there enough gp120 in the body fluids of HIV-1-infected individuals to have biologically significant effects? Virology 2004: 1-8

19. Blanco J, Barretina J, Ferri KF, Jacotot E, Gutierrez A, Cabrera C, Kroemer G, Clotet B and Este JA (2003) Cell-surface-expressed HIV-1 envelope induces the death of CD4 T cells during GP41-mediated hemifusion-like events. Virology 305: 318-329

20. Sylwester A, Murphy S, Shutt D and Soll DR (1997) HIV-induced T cell syncytia are self-perpetuating ant the primary cause of $T$ cell death in culture. J. Immunol. 158: 3996-4007

21. Ferri KF, Jacotot E, Geuskens M and Kroemer G (2000b) Apoptosis and karyogamy in syncytia induced by HIV-1-ENV/CD4 interaction. Cell Death Differ. 7: 1137-1139

22. Zhivotovsky B and Kroemer G (2004) Apoptosis and genomic instability. Nat. Rev. Mol. Cell. Biol. 5: 752-762

23. Andreau K, Perfettini J-L, Castedo M, Metivier D, Scott V, Pierron G and Kroemer $G$ (2004b) Contagious apoptosis facilitated by the HIV-1 envelope. Fusion-induced cell-to-cell transmission of a lethal signal. J. Cell. Sci. 117: 5643-5653

24. Catani MV, Corasaniti MT, Navarra M, Nistico G, Finazzi-Agro A and Melino G (2000) gp120 induces cell death in human neuroblastoma cells through the CXCR4 and CCR5 chemokine receptors. J. Neurochem. 74: 2373-2379

25. Garden GA, Guo W, Jayadev S, Tun C, Balcaitis S, Choi J, Montine TJ, Moller T and Morrison RS (2004) HIV associated neurodegeneration requires p53 in neurons and microglia. FASEB J. 18: 1141-1143
26. Hayward P (2004) Viral proteins cause cell death in HIV-associated dementia. Lancet Neurol. 3: 325

27. Xu Y, Kulkosky J, Acheampong E, Nunnari G, Sullivan J and Pomerantz RJ (2004) HIV-1-mediated apoptosis of neuronal cells: proximal molecular mechanisms of HIV-1-induced encephalopathy. Proc. Natl. Acad. Sci. USA 101: $7070-7075$

28. Barbaro G, Fisher SD and Lipshultz SE (2001) Pathogenesis of HIV-associated cardiovascular complications. Lancet Infect. Dis. 1: 115-124

29. Kapasi AA, Patel G, Franki N and Singhal PC (2002) HIV-1 gp120-induced tubular epithelial cell apoptosis is mediated through p38-MAPK phosphorylation. Mol. Med. 8: 676-685

30. Ray PE, Liu XH, Robinson LR, Reid W, Xu L, Owens JW, Jones OD, Denaro F Davis HG and Bryant JL (2003) A novel HIV-1 transgenic rat model of childhood HIV-1-associated nephropathy. Kidney Int. 63: 2242-2253

31. Vlahakis SR, Villasis-Keever A, Gomez TS, Bren GD and Paya CV (2003) Human immunodeficiency virus-induced apoptosis of human hepatocytes via CXCR4. J. Infect. Dis. 188: $1455-1460$

32. Berndt C, Möpps B, Angermüller S, Gierschik P and Krammer PH (1998) CXCR4 and CD4 mediate a rapid CD95-independent cell death in CD4+ cells. Proc. Natl. Acad. Sci. USA 95: 12556-12561

33. Finco O, Nuti S, De Magistris M, Mangiavacchi L, Aiuti A, Forte P, Fantoni A, van der Putten $\mathrm{H}$ and Abrignani S (1997) Induction of CD4+ T cell depletion in mice doubly transgenic for HIV gp120 and human CD4. Eur. J. Immunol. 27: 1319-1324

34. Hashimoto F, Oyaizu N, Kalyanaraman VS and Pahwa S (1997) Modulation of Bcl-2 protein by CD4 cross-linking: a possible mechanism for lymphocyte apoptosis in human immunodeficiency virus infection and for rescue of apoptosis by interleukin-2. Blood 1997: 745-753

35. Somma F, Tuosto L, Montani MS, Di Somma MM, Cundari E and Piccolella E (2000) Engagement of CD4 before TCR triggering regulates both Bax- and Fas (CD95)-mediated apoptosis. J. Immunol. 164: 5078-5087

36. Tuosto L, Marinari A and Piccolella E (2002) CD4-Lck through TCR and in the absence of Vav exchange factor induces Bax increase and mitochondrial damage. J. Immunol. 168: 6106-6112

37. Tuosto L, Piazza C, Moretti S, Modesti A, Greenlaw R, Lombardi G and Piccolella E (1995) Ligation of either CD2 or CD28 rescues CD4+ T cells from HIV-gp120-induced apoptosis. Eur. J. Immunol. 25: 2917-2922

38. Kaul M and Lipton SA (1999) Chemokines and activated macrophages in HIV gp120-induced neuronal apoptosis. Proc. Natl. Acad. Sci. USA 96: 8212-8216

39. Haughey NJ and Mattson MP (2002) Calcium dysregulation and neuronal apoptosis by the HIV-1 Proteins Tat and gp120. J. Acquir. Immune. Defic. Syndr. 31 (Suppl 2): S55-S61

40. Garden GA, Budd SL, Tsai E, Hanson L, Kaul M, D’Emilia DM, Friedlander RM, Yuan J, Masliah E and Lipton SA (2002) Caspase cascades in human immunodeficiency virus-associated neurodegeneration. J. Neurosci. 22: 4015-4024

41. Silva C, Zhang K, Tsutsui S, Holden JK, Gill MJ and Power C (2003) Growth hormone prevents human immunodeficiency virus-induced neuronal p53 expression. Ann. Neurol. 54: 605-614

42. Jordan-Sciutto KL, Wang G, Murphy-Corb M and Wiley CA (2000) Induction of cell-cycle regulators in simian immunodeficiency virus encephalitis. Am. J. Pathol. 157: 497-507

43. Blanco J, Barretina J, Clotet B and Este JA (2004) R5 HIV gp120-mediated cellular contacts induce the death of single CCR5-expressing CD4 T cells by a gp41-dependent mechanism. J. Leukocyte Biol. 76: 804-811

44. Blanco J, Jacotot E, Cabrera C, Cardona A, Clotet B, De Clercq E and Este JA (1999) The implication of the chemokine receptor CXCR4 in HIV-1 envelope protein-induced apoptosis is independent of the $G$ protein-mediated signalling. AIDS 13: 909-917

45. Ferri KF, Jacotot E, Blanco J, Esté JA, Zamzami A, Susin SA, Brothers G, Reed $\mathrm{JC}$, Penninger JM and Kroemer G (2000a) Apoptosis control in syncytia induced by the HIV-1-envelope glycoprotein complex. Role of mitochondria and caspases. J. Exp. Med. 192: 1081-1092

46. Kolesnitchenko V, Wahl LM, Tian H, Sunila I, Tani Y, Hartmann D-P, Cossman J, Raffeld M, Orenstein J, Samelson LE and Cohen DI (1995) Human immunodeficiency virus 1 envelope-initiated G2-phase programmed cell death. Proc. Natl. Acad. Sci. USA 92: 11889-11893

47. Blaak $H$, van't Wout $A B$, Brouwer M, Hoolbrink $B$, Hovenkamp $E$ and Schuitemaker $\mathrm{H}(2000)$ In vivo HIV-1 infection of CD45RA+ CD4+ T cells is 
established primarily by syncytium-inducing variants and correlates with the rate of CD4+ T cell decline. Proc. Natl. Acad. Sci. USA 97: 1269-1274

48. Lifson JD, Reyes GR, McGrath MS, Stein BS and Engleman EG (1986b) AIDS retrovirus-induced cytopathology: giant cell formation and involvement of CD4 antigen. Science 232: 1123-1127

49. Maas JJ, Gange SJ, Schuitemaker G, Coutinho RA, van Leeuwen R and Margolick JB (2000) Strong association between failure of $T$ cell homeostasis and the syncytium-inducing phenotype among HIV-1-infected men in the Amsterdam Cohort Study. AIDS 16: 1155-1161

50. Mohri H, Perelson AS, Tung K, Ribeiro RM, Ramratnam B, Markowitz M, Kost R, Hurley A, Weinberger L, Cesar D, Hellerstein MK and Ho DD (2001) Increased turnover of T lymphocytes in HIV-1 infection and its reduction by antiretroviral therapy. J. Exp. Med. 194: 1277-1287

51. Scheller C and Jassoy C (2001) Syncytium formation amplifies apoptotic signals: a new view on apoptosis in HIV infection in vitro. Virology 30: 48-55

52. Camerini D, Su HP, Gamez-Torre G, Johnson ML, Zack JA and Chen IS (2000) Human immunodeficiency virus type 1 pathogenesis in SCID-hu mice correlates with syncytium-inducing phenotype and viral replication. J. Virol. 74: 3196-3204

53. Etemad-Moghadam B, Sun Y, Nicholson EK, Fernandes M, Liou K, Gomila R Lee J and Sodroski J (2000) Envelope glycoprotein determinants of increased fusogenicity in a pathogenic simian-human immunodeficiency virus (SHIVKB9) passaged in vivo. J. Virol. 74: 4433-4440

54. Castedo M and Kroemer G (2002) The beauty of death. Trends Cell Biol. 12 446-447

55. Castedo M, Ferri KF, Blanco J, Roumier T, Larochette N, Barretina J Amendola A, Nardacci R, Metivier D, Este JA, Piacentini M and Kroemer G (2001) Human immunodeficiency virus 1 envelope glycoprotein complexinduced apoptosis involves mammalian target of rapamycin/FKBP12 rapamycin-associated protein-mediated p53 phosphorylation. J. Exp. Med. 194: 1097-1110

56. Boya P, Roumier T, Andreau K, Gonzalez-Polo R-A, Zamzami N, Castedo M and Kroemer $G$ (2003) Mitochondrion-targeted apoptosis regulators of viral origin. Biochem. Biophys. Res. Commun. 304: 575-581

57. Castedo M, Perfettini J-L, Medema JP and Kroemer G (2004a) Cell death by mitotic catastrophe: a molecular definition. Oncogene 23: 2825-2837

58. Castedo M, Perfettini J-L, Roumier T, Valent A, Raslova H, Yakushijin K, Horne DA, Feunteun J, Lenoir G, Vainchenker W and Kroemer G (2004b) Mitotic catastrophe. A special case of apoptosis preventing aneuploidy. Oncogene 23: 4362-4370

59. Castedo M, Perfettini J-L, Roumier T, Yakushijin K, Horne DA, Medema R and Kroemer G (2004c) Chk2 is a negative regulator of mitotic catastrophe. Oncogene 23: 4353-4361

60. Roumier T, Castedo M, Perfettini J-L, Andreau K, Metivier D, Zamzami N and Kroemer G (2003) Mitochondrion-dependent caspase activation induced by the HIV-1 envelope. Biochem. Pharmacol. 66: 1321-1329

61. Perfettini J-L, Roumier T, Castedo M, Larochette N, Boya P, Reynal B, Lazar V, Ciccosanti F, Nardacci R, Penninger J, Piacentini M and Kroemer G (2004b) NF-kB and p53 are the dominant apoptosis-inducing transcription factors elicited by the HIV-1 envelope. J Exp Med 199: 629-640
62. Castedo M, Roumier T, Blanco J, Ferri KF, Barretina J, Tintignac LA, Andreau K, Perfettini J-L, Armendola A, Nardacci R, LeDuc P, Ingber DE, Druillennec S, Roques B, Leibovitch SA, Vilella-Bach M, Chen J, Este JA, Modjtahedi N, Piacentini $M$ and Kroemer $G$ (2002b) Sequential involvement of Cdk1, mTOR and p53 in apoptosis induced by the human immunodeficiency virus-1 envelope. EMBO J. 21: 4070-4080

63. Ferri KF, Jacotot E, LeDuc P, Geuskens M, Ingber DE and Kroemer G (2000c) Apoptosis of syncytia induced by HIV-1-envelope glycoprotein complex. Influence of cell shape and size. Exp. Cell Sci. 261: 119-126

64. Green DR and Kroemer G (2004) The pathophysiology of mitochondrial cell death. Science 305: 626-629

65. Castedo M, Perfettini J-L, Roumier T and Kroemer G (2002a) Cyclin-dependent kinase-1: linking apoptosis to cell cycle and mitotic catastrophe. Cell Death Differ. 9: 1287-1293

66. Perfettini J-L, Castedo M, Nardacci R, Ciccosanti F, Boya P, Roumier T, Larochette N, Piacentini M and Kroemer G (2005) Essential role of p53 phosphorylation by 38 MAPK in apoptosis induction by the HIV-1 envelope. J. Exp. Med. 201: 279-289

67. Genini D, Sheeter D, Rought S, Zaunders JJ, Susin SA, Kroemer G, Richman DD, Carson DA, Corbeil J and Leoni LM (2001) HIV induced lymphocyte apoptosis by a p53-initiated, mitochondrion-mediated mechanism. FASEB J. 15: $5-6$

68. Petit F, Arnoult D, Lelievre JD, Parseval LM, Hance AJ, Schneider P, Corbeil J, Ameisen JC and Estaquier J (2002) Productive HIV-1 infection of primary CD4+ $T$ cells induces mitochondrial membrane permeabilization leading to caspaseindependent cell death. J. Biol. Chem. 277: 1477-1487

69. Banki K, Hutter E, Gonchoroff NJ and Perl A (1998) Molecular ordering in HIVinduced apoptosis-Oxidative stress, activation of caspases, and cell survival are regulated by transaldolase. J. Biol. Chem. 273: 11944-11953

70. Muthumani K, Wadsworth SA, Dayes NS, Hwang DS, Choo AV, Abeysinghe HR, Siekierka JJ and Weiner DB (2004) Suppression of HIV-1 viral replication and cellular pathogenesis by a novel p38/JNK kinase inhibitor. AIDS 18: 739-748

71. Cannavo G, Paiardini M, Galati D, Cervasi B, Montroni M, De Vico G, Guetard D, Bocchino ML, Picerno I, Magnani M, Silvestri G and Piedimonte G (2001) Abnormal intracellular kinetics of cell-cycle-dependent proteins in lymphocytes from patients infected with human immunodeficiency virus: a novel biologic link between immune activation, accelerated T-cell turnover, and high levels of apoptosis. Blood 97: 1756-1764

72. Piedimonte G, Corsi D, Paiardini M, Cannavo G, lentile R, Picerno I, Montroni M, Silvestri $G$ and Magnani M (1999) Unscheduled cyclin B expression and $\mathrm{p} 34 \mathrm{cdc} 2$ activation in T lymphocytes from HIV-infected patients. AIDS 13: 1159-1164

73. Amendola A, Gougeon ML, Poccia F, Bondurand A, Fesus L and Piacentini $M$ (1996) Induction of "tissue" transglutaminase in HIV pathogenesis: Evidence for high rate of apoptosis of CD4+ T lymphocytes and accessory cells in lymphoid tissues. Proc. Natl. Acad. Sci. USA 93: 11057-11062

74. Andreau K, Castedo M, Perfettini J-L, Roumier T, Pichart E, Souquere S, Vivet $\mathrm{S}$, Larochette N and Kroemer G (2004) Pre-apoptotic chromatin condensation upstream of the mitochondrial checkpoint. J. Biol. Chem. 279: 55937-55945 